\title{
JORNAL NA ESCOLA: DA INFORMAÇÃO À OPINIÃO ESCLARECIDA
}

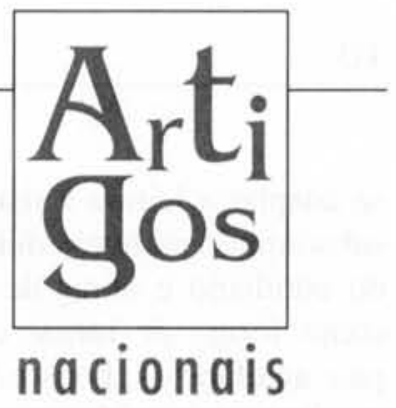

\section{Trabalho pedagógico com o jornal desenvolve hábito de leitura e ajuda a criar elo entre a sala de aula e a realidade social}

Este artigo é resultado de pesquisas e reflexões realizadas por um grupo interdisciplinar de professores da Universidade Estadual de Maringá-PR, envolvido na execução do Projeto Hemeroteca Pedagógica ${ }^{1}$. Sua elaboração se impôs por dois motivos: o primeiro, para organizar e destacar as principais discussões sobre o uso do jornal na educação escolar, em grande parte resultado de experiências desenvolvidas em todo o país, muitas por iniciativa das próprias empresas jornalísticas; o segundo, para marcar a importância e as condições básicas necessárias para que esse recurso ajude a desenvolver no aluno o gosto pela leitura, possibilite perceber os diferentes pontos de vista e melhore sua compreensão da realidade social.

$\mathrm{O}$ jornal, enquanto recurso de ensino, ainda não faz parte da rotina de sala de aula da maioria das escolas brasileiras. Isto não é uma característica nacional. Nos Estados Unidos, ressalvadas as distâncias espacial e temporal e as especificidades próprias de um país desenvolvido, apesar de ter seu uso recomendado desde 1932, a sistematização de sua prática só se deu em 1955. Na Europa não foi diferente. Fica evidente também que sua utilização, quando ocorreu, esteve muito mais vinculada ao trabalho de empre- sas jornalísticas no sentido de atualizar seu conteúdo e obter mais qualidade na consecução de seus objetivos do que à iniciativa da própria escola.

Em seu artigo $O$ jornal e sua história, Faria $^{2}$ atribui ao jornal Zero Hora, de Porto Alegre-RS, o pioneirismo desse trabalho no Brasil. Este jornal mantém programas para professores e alunos desde 1980. A partir de então, atividades semelhantes passaram a ser desenvolvidas por outros jornais, de diversas regiões. No início de 1996, a Associação Nacional de Jornais - ANJ - divulgou propostas de vinte e cinco jornais, de circulação nacional, estadual ou regional, que mantêm algum tipo de trabalho com escolas. Ao lado disso, começam a aparecer trabalhos acadêmicos sobre a importância do uso desse material em sala de aula. Um exemplo é a tese de doutorado de Sílvia Bueno Terzí ${ }^{3}$, que mostra a necessidade de

\section{AS AUTORAS}

Maria de Lourdes Longhini Trevisani Ana Lúcia Olivo Rosas Moreira Maria Terezinha Bellanda Galuch Marta Sueli de Faria Sforni

Professoras da Universidade Estadual de Maringá-PR.

1. Projeto patrocinado pela Fundação Vitae e desenvolvido entre fevereiro de 1996 e junho de 1997.

2. FARIA, Maria Alice. O jornal e sua história. Proleitura. Assis, São Paulo: UNESP, Ano 2, n. 5, jun. 1995 . p.3.

3. TERZI, Sílvia Bueno. A construção da leitura: uma experiência com crianças de meios iletrados. Campinas: Edunicamp, 1995. 165p. 
se adaptar a leitura à realidade dos alunos, substituindo os livros didáticos por notícias do cotidiano e obras de literatura infantil, como forma de tornar crianças, filhas de pais analfabetos, bons e interessados leitores. Por sua vez, Marques de $\mathrm{Melo}^{4}$ vê o jornal como um meio que possibilita o desenvolvimento da consciência cidadã, tornando as crianças leitoras não só de textos mas do mundo.

Em favor do uso do jornal em sala de aula está ainda a questão da língua escrita enquanto modelo utilizado e valorizado socialmente. Conforme destaca Faria, apoiada em Nílson Lage, “... a linguagem jornalística oferece uma espécie de 'português fundamental', uma língua base, não tão restrita que limite o crescimento lingüístico do aluno e nem tão ampla que torne difícil ou inacessível o texto escrito ao comum dos estudantes"s.

Percebe-se que a defesa do uso do jornal na educação escolar extrapola a preocupação de perpetuar o hábito puro e simples de ler jornais. Entende-se que sua utilização representa um compromisso político com a formação contínua do aluno-leitor.

\section{JORNAL E LEITURA DO MUNDO}

Essa necessidade se impõe à medida que, observando a sociedade nos dias de hoje, não é difícil perceber as mudanças que ela vem passando, as quais foram muito bem sintetizadas por Santos: globalização da economia, disseminação planetária de informações e imagens, problemas de natureza econômica (desemprego, altas taxas de juros, crise financeira do EstadoPrevidência, dívida externa), translocalização maciça de pessoas, mudança do papel do Estado e das políticas educacionais decorrentes desse processo. O desenvolvimento tecnológico, além de modernizar o sistema de produção, põe em xeque leis sociais consideradas necessárias e justas até pouco tempo atrás.

O questionamento e a crítica às leis vigentes provocam uma pluralidade de valores, de comportamentos contraditórios, de ações indefinidas, de incertezas quanto àquilo que a educação deve perseguir; bem como a desestabilização de normas familiares, religiosas, educacionais, filosóficas, políticas e outras.

As mudanças ocorridas na sociedade $\mathrm{e}$ a decorrente ausência de consenso em torno de suas leis põem a necessidade de repensar a formação do homem. Essa necessidade faz com que a educação, principalmente a escolar, ocupe o centro de muitas das discussões atuais e a transforme em alvo, ora de críticas, ora de propostas que objetivam superar práticas até então tidas como legítimas e úteis.

Diante dessa problemática, objetivos antes não enfatizados começam a ser valorizados na educação e em específico no trabalho escolar. Formação de cidadãos sintonizados com o dia-a-dia da região, do país e do mundo e sensibilizados com os problemas sociais é o principal deles. Decorrente disso, a reflexão sobre a realidade social é uma capacidade que se impõe desenvolver. Tal reflexão passa necessariamente por uma interpretação mais consistente do vivido e das explicações que the são dadas, para superar as

4. Apud FARIA, Maria Alice. O jornal na sala de aula. 4.ed. São Paulo: Contexto, 1994. p.13.

5. FARIA, Maria Alice. O jornal... op.cit. p. 12

6. SANTOS, Boaventura de Souza. Pela mão de Alice: o social e o político na pós-modernidade. Porto: Apontamento, 1994. 
justificativas que reforçam diferenças entre indivíduos e grupos, que naturalizam as relações de dominação ${ }^{7}$. Essa interpretação tem como condição prévia a democratização do universo de informações existentes e a leitura se apresenta como um dos meios para viabilizar tal objetivo.

Nesse sentido, a leitura e a compreensão das mensagens passam a ser instrumentos insuficientes, mas são pré-requisitos para se chegar à interpretação e análise das informações sem que se façam julgamentos morais ou leituras idealizadas antes mesmo de se compreender os fatos no espaço e contexto social em que foram produzidos. É isso que dá a dimensão do ato de ler nos dias atuais. É preciso atentar para o conteúdo das mensagens.

Por outro lado, dados da avaliação realizada pelo Ministério da Educação e Desporto com alunos de quartas e oitavas séries do ensino fundamental e com alunos do terceiro ano do ensino médio, divulgados pela Folha de S. Paulo, evidenciam as dificuldades na formação dos leitores que passam pela escola: "somente um por cento dos alunos do terceiro ano do segundo grau conseguiu responder corretamente às questões de Português que exigem comparação entre textos de naturezas diversas, estabelecimento de relações de causa e efeito e a percepção de crítica, ironia e humor"8.

Uma das propostas para a escola contemporânea refere-se especificamente à formação do leitor que conhece os fatos e fenômenos e reflete sobre eles. Estudiosos de diferentes áreas não só reafirmam a importância da leitura na formação do aluno, como destacam que é o melhor que a escola pode oferecer, pois muito do que se aprende, não só na escola mas também na vida, pode-se obter por meio da leitura. O desenvolvimento do hábito de ler se estabelece com mais facilidade se estiver relacionado a situações de comunicação real e com a função de preservar a informação. Portanto, a leitura informati /a e atualizada constitui-se em importante recurso. $O$ pouco espaço que esta tem encontrado na escola contrasta com a marcante presença e disponibilidade dos meios de comunicação na sociedade atual.

O trabalho com o jornal na sala de aula, além de possibilitar o enriquecimento e atualização do conteúdo escolar, contribui para que as informações e opiniões veiculadas se apresentem como um canal aberto entre a sala de aula e a dinâmica da realidade social, levando o pensamento não à conformação, mas à crítica e à participação.

Sob esse ponto de vista, os jornais cumprem uma ampla função na instituição escolar: oferecem dados ao mesmo tempo em que os assuntos despertam a atenção dos alunos para questões de sua realidade e conseqüentemente provocam o interesse para outras informações. Este recurso é mais rico, por exemplo, que o livro didático devido à atualidade dos temas, aliada à clareza e à objetividade da linguagem, as quais estimulam a comunicação, uma vez que as notícias, com diferentes mensagens e formas reportagens, artigos, resultados de pesquisas, informações de serviços, colunas, manchetes, fotografias, charges -, são a sua matéria-prima.

7. SCHIFF, Michel. A inteligência desperdiçada: desigualdade social, injustiça escolar. Porto Alegre: Artes Médicas Sul, 1993.

8. FALCÃO, Daniela. Testes aplicados em 2.800 escolas revelam que alunos não sabem questōes básicas de Matemática e Português. Folha de S. Paulo, 26 nov. 1996, Caderno 3, Cotidiano. p.1. 


\section{LEITURA CRÍTICA DO JORNAL}

Não se pode esquecer, porém, de que a difusão desse meio de comunicação, com ênfase na sociedade de consumo, muitas vezes se atém à superficialidade do conhecimento, dificultando o relacionamento e aprofundamento dos temas. A linguagem jornalística se apresenta marcada também por concepções ideológicas e por interesses políticos, empresariais, de mercado, entre outros. O jornal é uma empresa capitalista, como afirma Sodré9, destacando que a história da imprensa é a própria história do desenvolvimento do capital. De maneira semelhante às demais empresas existentes, a imprensa escrita se sustenta da venda deste produto e principalmente da publicidade que custeia suas despesas. Esta ausência de neutralidade pode gerar várias versões sobre um tema. Os meios de comunicação tornam-se, assim, um poderoso instrumento de formação de opinião, ou "indústrias de consciência", conforme afirma Marques de Melo, no livro Jornal laboratório ${ }^{10}$.

Mas, se por um lado, a superficialidade e a diversidade de enfoques permitem críticas ao uso do jornal em sala de aula, por outro, encontra aí a sua relevância, justamente por apresentar um mundo não-harmônico; ao contrário do que, às vezes, a escola tende a mostrar. Ele evidencia os diferentes grupos que compõem a sociedade e suscita discussões sobre sua atuação. Além disso, as versões para um mesmo fato constituem-se num material importante para o desenvolvimento do espírito crítico, ao mesmo tempo que torna possível ordenar e hierarquizar as informações recebidas pela mídia, oferecendo subsídios ricos e dinâmicos para a compreensão da realidade.
O desenvolvimento da capacidade de seleção e crítica da informação está intimamente ligado ao papel do professor em sala de aula. É ele que pensa e organiza situações, estimula a curiosidade para a formação do leitor que, através das informações, amplia seu horizonte cultural, desenvolve a sensibilidade para $o$ aprofundamento dos fatos e estabelece relações. O professor é o elo entre a informação e o entendimento.

Alcançar este objetivo pressupõe que o professor seja, ele próprio, este leitor e que compreenda a importância desse trabalho na escola. Um professor que busque informações não só em sua área específica de conhecimento, mas que também as relacione com o processo social, refletindo sobre os acontecimentos, ações e decisões que perpassam o contexto nacional e internacional, bem como suas implicações. Por essa via, tem condições de criar no aluno o hábito do estudo, desenvolvendo o prazer pela leitura enquanto meio de ingressar no mundo do saber e da cultura. Com isso se quer destacar que a criança, sobretudo a que não tem esse estímulo em casa, dificilmente adquire autonomia para ler compreensiva e analiticamente sem ajuda. Desta forma, não basta que a escola coloque à disposição do aluno, na sala de aula ou na biblioteca, jornais e revistas para que escolham de forma aleatória o que vão ler. Tal atividade, ao não requisitar intervenção pedagógica, pode ser válida, mas não enquanto trabalho escolar, já que este requer sistematização. $\mathrm{O}$ valor educativo do uso de textos informativos em sala de aula está justamente na sua exploração. Os artigos jornalísticos se constituem

\footnotetext{
9. SODRÉ, Nelson Werneck. História da imprensa no Brasil. 2.ed., Rio de Janeiro: Graal, 1977.

10. LOPES, Dirceu Fernandes. Jornal laboratório: do exercício escolar ao compromisso com o público leitor. São Paulo: Summus, 1989. p. 41.
} 
em roteiros de estudo para discutir aspectos econômicos, políticos, geográficos, científi$\cos$, históricos, problemas sociais, avanços tecnológicos etc. $\mathrm{O}$ desenvolvimento de es- truturas cognitivas que permitam compreender o que se ouve e o que se lê requer uma ação educativa intencional, metodologicamente planejada e executada.

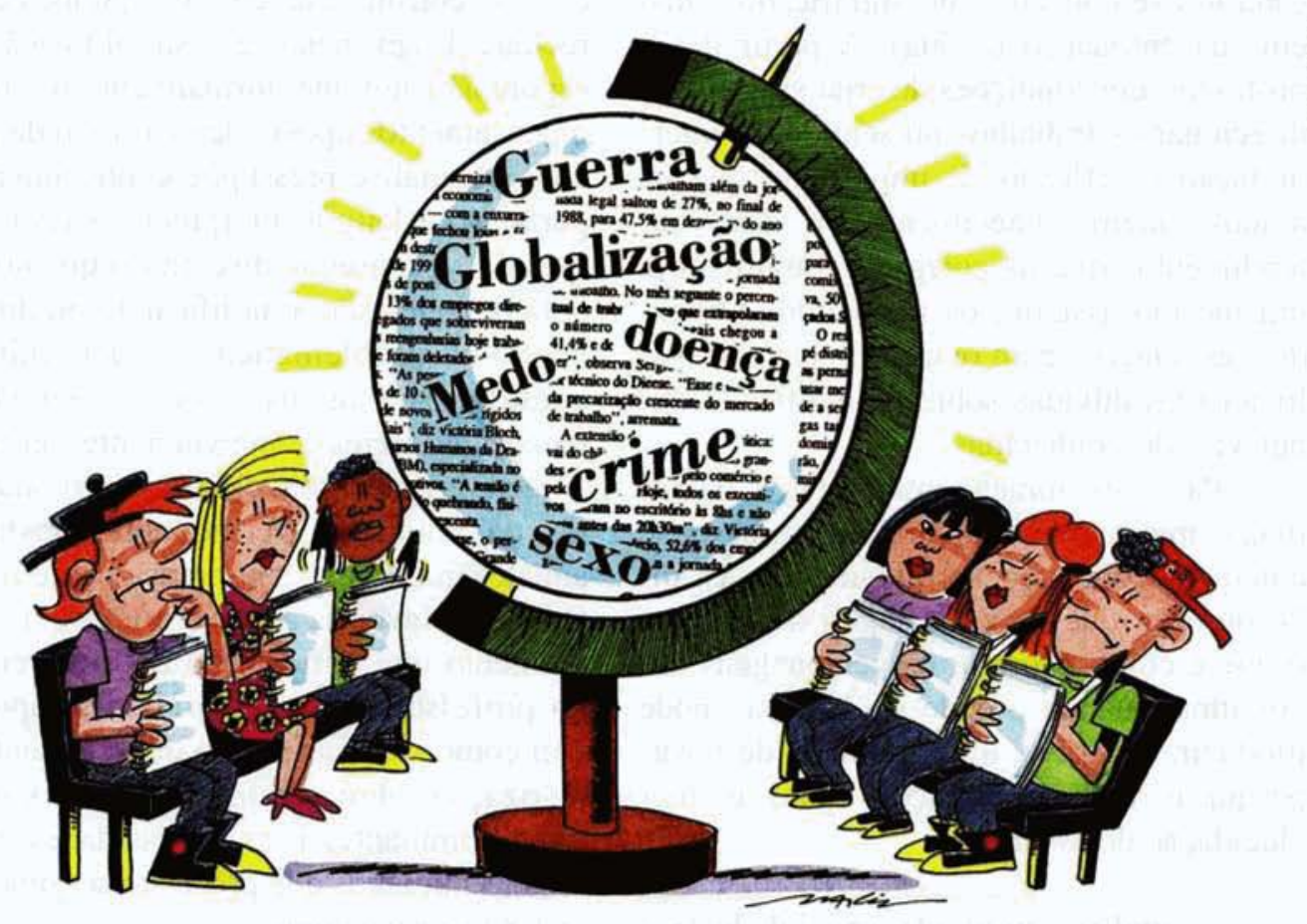

É preciso ajudar a criança a familiarizar-se com o jornal desde os primeiros anos de escolaridade. Diferentes atividades devem ser organizadas para tal fim, que vão desde o conhecimento sobre a organização do jornal - cadernos, seções, ilustrações, primeira página - e os diferentes tipos de textos até o domínio da terminologia específica: nome do jornal, manchete, índice, lide, caixa/box, legenda, títulos etc. Dante Mantiussi, diretor editorial da revista Imprensa, afirma que "a simples discussão diária de uma primeira página aumentaria o nível de informação do aluno e estimularia o hábito da leitura" 11 .
A percepção das semelhanças e diferenças entre vários jornais (locais, regionais, nacionais e internacionais) também é importante para o desenvolvimento do pensamento analítico, não só em termos de diagramação e linguagem, mas sobretudo pela similitude do comportamento humano, dos problemas sociais, do desenvolvimento e uso da tecnologia, marcada pela globalização, apesar da distância espacial e das especificidades locais.

Um outro ponto a ser considerado é que o texto jornalístico surtirá maiores efeitos na formação do leitor quando a mesma notícia/informação for comum a todos os

11. MATIUSSI, Dante. Jornalistas defendem o jornal na escola. Proleitura. Assis, São Paulo: Unesp, ano 2, n.5, jun. 1995. p.1. (Entrevista). 
alunos. Lida pelo professor, para a turma, enquanto ainda não domina o código escrito; depois, pelos próprios alunos, de preferência em voz baixa (silenciosa), para que cada um se concentre no significado e não em sua entonação (a fala). A partir daí o professor tem condições de criar situações e direcionar os trabalhos no sentido da interpretação e reflexão. É importante que os alunos tomem conhecimento dos vários entendimentos que os colegas geraram sobre um mesmo assunto, os raciocínios utilizados, as relações com outros temas, após solucionadas dúvidas sobre o significado das palavras desconhecidas.

Para a exploração interpretativa da notícia é preciso que os alunos e o professor se coloquem como aqueles que irão reconstruíla, ou seja, que os fatos sejam decifrados: o que e como ocorreu, os personagens envolvidos, quando e onde se deu. Isto pode produzir, inclusive, a necessidade de novas pesquisas e/ou informações para melhor elucidação do assunto.

A análise, momento crucial do trabalho, não se resume em fazer um julgamento moral sobre a notícia lida, a partir de questionamentos sobre a opinião dos alunos no parâmetro do certo ou errado, do justo ou injusto. A complexidade do comportamento social, político e econômico contemporâneo não pode ser simplificada através da cristalização do bem e do mal. Questões deste tipo, além de inadequadas, passam para segundo plano ou mesmo comprometem o entendimento das relações sociais em suas contradições.

Tal modelo de análise não se sustenta quando o indivíduo de forma autônoma se vê em face das múltiplas determinações da realidade. Com isso, não se está afirmando que a interpretação e a análise não devam conduzir à tomada de posturas frente às mensagens veiculadas, mas que as informações se consubstanciem em opiniões esclarecidas. Logo, nega-se a simplificação e o espontaneísmo que normalmente permeiam o pensamento supostamente crítico da realidade. A análise pressupõe conhecimento e, portanto, a leitura interpretativa leva a ela quando se consegue discernir o quanto uma notícia pode estar simplificando ou direcionando a problemática de determinadas questões para alguns aspectos, segundo intenções e interesses previamente definidos. À medida que se tem clareza dos fundamentos da notícia, a versão apresentada por aqueles que fazem a imprensa perde importância em favor da análise reflexiva. É nesse momento que a mediação e a interferência do professor são necessárias e se apresentam como valiosas para o desvelamento e a teorização sobre as estruturas sociais, os valores dominantes e as necessidades e problemas humanos que precisam ser objeto de reflexão e ação comuns.

Vale reforçar aqui a idéia defendida por Ciro Marcondes Filho: "há (...) três elementos que jogam do lado do receptor, impedindo que a manipulação surta efeito: a memória, a vivência e a visão de conjunto. As três supõem reserva de informação anterior. A informação é a principal arma contra a manipulação"12. Portanto, a análise autônoma e esclarecida, que passa necessariamente pelo conhecimento, pode ser provocada através do trabalho com o jornal em sala de aula.

A partir da leitura informativa e mediada pelo professor, é possível desenvolver no aluno uma estrutura cognitiva plena de relações causais, temporais e espaciais tornando 


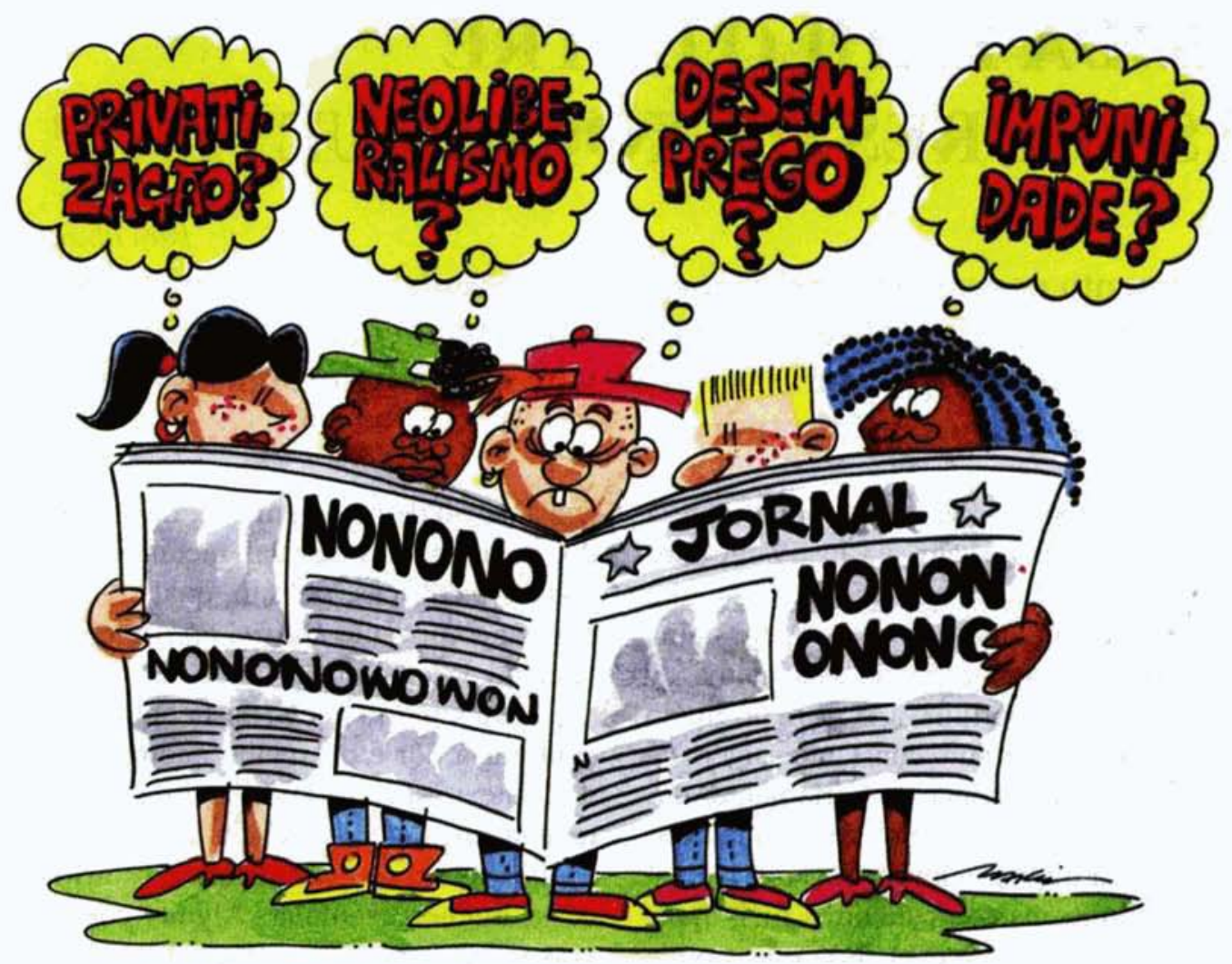

as suas operações mentais cada vez mais complexas e significativas, possibilitandolhe compreender melhor sua vida pessoal, da

Resumo: $\mathrm{O}$ artigo apresenta-se como resultado de pesquisas e reflexões realizadas por professoras da Universidade Estadual de Maringá-PR, envolvidas no projeto Hemeroteca Pedagógica. Discute a importância do trabaIho com o jornal em sala de aula, destacando o papel que ele pode desempenhar como facilitador da leitura da realidade, ajudando a desenvolver, nas crianças e jovens, o espirito crítico tão importante na atualidade. Destaca, ainda, a linguagem jornalística como acessivel e de fácil compreensāo, ajudando a criar o hábito de leitura.

Palavras-chave: jornal, Hemeroteca Pedagógica, leitura, ensino-aprendizagem comunidade em que vive e capacitando-o para apropriar-se da cultura cada vez mais universalizada.

Abstract: The article is presented as a result of research and reflections carried out by professors from Universidade Estadual de Maringá-PR, involved in the Hemeroteca Pedagógica (Teaching Library) project. The importance of the work with newspapers in the classroom is discussed, stressing the role it can have as an instrument to ease the reading of reality, helping one to develop, among children and young people, the critical spirit that is so important nowadays. It also emphasizes the journalistic language as accessible and easy to understand, something that helps one to create the reading habit.

Key words: newspaper, Hemeroteca Pedagógica, reading, teaching 